\title{
O Código Brasileiro de Defesa do Consumidor e o MERCOSUL
}

Trabalho apresentado no seminário "MERCOSUL: Livre Circulação de mercadorias e proteção do consumidor", dezembro de 1993, Faculdade de Direito UFRGS.

\section{Cláudia Lima Marques}

Professora da UFRGS, Mestre em Direito pela Univ. de Tübingen

Especialista em Integração Européia pelo Europa-Institut, Saarbruecken, Alemanha

SUMÁRIO

Introdução; I. O Código Brasileiro de Defesa do Consumidor como lei protetora dos consumidores do MERCOSUL; A) Natureza da lei protetora; 1. Origem constitucional do CDC; 2. CDC como norma de ordem pública 3. Nite publica, 3. Norma B) O CDC como matéria a harmonizar; Conclusão.

\section{Abstract}

Das thema dieses Artikels ist das neue brasilianische Verbraucherschutzgesetz (CDC) aus der Sicht des MERCOSUL, des gemeinsamen Marktes zwischen Argentinien, Brasilien, Uruguay und Paraguay.

Der erste Teil analysiert den $C D C$ als Schutzgesetz in Brasilien, seine Natur, seine verfassungsgebotene Hierarchie und sein Anwendungsbereich, wobei auf den noch schwach ausgebauten Verbraucherschutz in den anderen Mercosul-Län dern bingezwiesen wird.

Im zweiten Teil wird der CDC als eventuelles Hindernis für den freien Handelsverkehr analysiert, der eine Massnabme gleicher Wir kung wie Zölle sein kann, und der somit ein Thema für die Rechtsharmonisierung darstellt, wobei die aktuellen Linien der EG (Minimale Richtlinien, Subsidiaritätsprinzip und das Vers cblechterungsverbot) beacbtet werden sollten.

Introdução

lema do grande jurista holandês Tobias Asser, fundador há cem anos da Conferência de Haia de Direito Internacional Privado, dedicada à unificação e à harmo- bore e instrumentalize esta integração. Afinal, o MERCOSUL não poderá sobrevive e evoluir como um fenômeno merament político e econômico, desacompanhado de uma base estrutural sólida, de normas de conduta confiáveis e seguras para os seus indivíduos e de instrumentos de manifestação efetivos e democráticos ${ }^{8}$. Nesse sentido recorro às sábias palavras de Asser, de paciência com as dificuldades, mas também de coragem para repensar a realidade socia existente e proponho como tema de estudo a proteção dos direitos humanos no âmbito do MERCOSUL, especificamente a proteção dos direitos fundamentais de $2^{\underline{2}}$ geração, os direitos sociais e econômicos, entre os quais se encontra a proteção dos interesses do consumidor.

Em verdade, já o preâmbulo do Tratado de Assunção institui como finalidade básica desse processo de integração a melhoria das "condições de vida de seus habitantes". A proteção dos interesses do consumidor deve ser, portanto, uma das políticas básicas durante a formação do MERCOSUL. Na visão econômica, porém, uma lei protetora dos interesses dos consumidores pode vir a restringir (ou dificultar) a entrada e o consumo de mercadorias e serviços oriundos de outros países do mercado comum, que não possuam nível igual de preocupação com a qualidade, informação e segurança dos produtos. Em outras palavras, um conjunto de normas legais dedicadas à tutela dos consumidores de um determinado país pode funcionar como uma barreira, neste caso barreira não-tarifária, à liberdade de circulação de produtos e serviços naquela zona de livre comércio e futuro mercado comum.

São duas visões do mesmo fenômeno jurídico, uma que tende a manter este corpo de normas tutelares, como uma conquist social, e outra que tende a revogar ou modificar as normas consideradas prejudiciais à integração econômica. Qual destas visões prevalecerá no MERCOSUL é dificil prever no momento. Também a da Comunidade Européia teve de enfrentar a matéria e tor nou-se uma das grandes legisladoras no tema da defesa do consumidor'. Se no in- cio, porém, sua tendência era de harmonizar as legislações nacionais, forçando a sua modificação para atingir somente o nível médio exigido para o bom funcionamento do mercado unificado, hoje sua ação legislativa é diferenciada ${ }^{10}$, tendente a exigir que os países sem legislação específica instituam-na, para atingir o requerido nível médio, mas a permitir que os outros Estados mantenham níveis mais altos de proteção de seus cidadãos ${ }^{11}$.

Examinando a situação atual da legislação dos quatro países do MERCOSUL, observa-se que somente o Brasil possui um rígido Código de Proteção à segurança, à saúde e aos interesses econômicos dos consumidores, enquanto na Argentina acaba-se de aprovar a Ley 24.240, em 13 de outubro de 1993, tímida Ley de Defensa del Consumi$d o r$, que após inúmeros vetos regula apenas os aspectos contratuais da proteção do consumidor; já nos dois outros paises vigoram os princípios voluntaristas tradicionais ${ }^{12}$.

Sendo assim, mister que se examine mais profundamente a legislação brasileira, em especial o Código de Defesa do Consumidor (Lei $\mathrm{n}^{\circ} 8.078 / 90$ ), na ótica da futura integração, tanto como uma lei protetora de direitos fundamentais (Parte I deste trabalho), quanto como uma lei discriminatória e limitadora do comércio, e os esforços que estão sendo feitos para manter os direitos conquistados e para substituí-los por uma legislação unitária e média para os quatro países do MERCOSUL (Parte II deste estudo).

\section{O Código Brasileiro de Defesa do} Consumidor comg lei protetora dos consumidores no MERCOSUL

A Lei 'no 8.078/90, conhecida como Código de Defesa do Consumidor (CDC), possui aplicação territorial limitada ao Estado brasileiro. Seu campo de aplicação ratione personae é, porém, amplo, assegurando novos direitos a pessoas físicas e jurídicas (os consumidores definidos nos artigos 2, $17 \mathrm{e}$ 29), nacionais e estrangeiras, e impondo novos deveres aos fornecedores, pessoas físicas 
e jurídicas, públicas ou privadas, nacionais ou estrangeiras (definidos em seu art. $3^{\circ}$ ).

Desta maneira, introduzindo no mercado brasileiro um produto de origem argentina, paraguaia ou uruguaia, submete-se o fabricante, produtor e mesmo o importador ao novo regime de responsabilidade previsto no CDC para os danos oriundos de defeito do produto ou para os seus vícios de qualidade, quantidade e informação. $\mathrm{Da}$ mesma maneira, se uma empresa estrangeir prestar serviços no mercado brasileiro, os contratos fechados entre este fornecedor de serviços e os consumidores do mercado brasileiro submetem-se aos novos patamares de equilíbrio e boa-fé exigidos pelo CDC. Trata-se, portanto, de uma lei básica para mercado brasileiro, isto sem falar nas suas inovações processuais e novas regras administrativas e penais introduzidas. Muitos dos riscos antes transferidos contratualmente ao consumidor (e, anteriormente, ao comerciante final) não mais podem ser transferidos por uma imposição ex lege. Mister, portanto, que se analise com mais vagar a natureza e o conteúdo desta lei, em especia os direitos fundamentais que assegura ao consumidor no mercado brasileiro.

\section{A) Natureza da lei protetora}

Analisando o CDC sob a ótica de le protetora de um grupo social específico, os consumidores no mercado brasileiro, podemos destacar três qualidades especiais: sua origem constitucional, sua definição como norma de "ordem pública" e sua caracter zação como norma de "interesse social".

1. Origem Constitucional do CDC

A Constituição Federal de 1988 em dois momentos menciona a defesa do consumidor, em seu art. 50, inciso XXXII, como direito fundamental, e no art. 170 , inciso $\mathrm{V}$, como princípio orientador $\mathrm{da}$ ordem econômica no Brasil ${ }^{13}$.

A origem constitucional da defesa do consumidor, tanto como direito fundamental, quanto princípio macroeconômico, deve ser destacada, uma vez que a tradição jurídica brasileira é de primazia da ordem constitucional em relação aos Tratados in ternacionais ${ }^{14}$. Nesse sentido, no Brasil, um ato internacional, mesmo que oriundo de um organismo supranacional, pode ser considerado inconstitucional e ter a sua não-obrigatoriedade no país declarada pelo Poder Judiciário, em controle abstrato (art. 102, I, letra $a, \mathrm{da}$ CF) ou em controle concreto de sua inconstitucionalidade (art. 102, II, $b$, art. 105, III $b$, art. 109, III, todos da Constituição Federal) $)^{15}$.

A primazia do texto da Constituição frente aos atos internacionais considerados inconstitucionais pelo Judiciário brasileiro não será superada, nem com base no disposto no parágrafo único do art. $4^{\circ} \mathrm{da}$ Constituição Federal, que institui a integração latino-americana como um dos princípios das relações exteriores da República, nem como defendem alguns ${ }^{16}$ pelo disposto no $\S 2^{\circ}$ do art. 5ㅇ da Lei Magna.

Em verdade, o referido $\S 2^{\circ}$ finaliza a lista de direitos fundamentais do art. 5\%, afirmando que: "Os direitos e garantias expressos nesta Constituição não excluem outros decorrentes do regime e dos princípios por ela adotados, ou dos tratados internacionais em que a República Federativa do Brasil seja parte." Nesse sentido, antes de quebrar o sistema dualista tradicional brasileiro com uma interpretação extensiva da norma, é necessário observar que entre as normas oriundas do direito internacional há aquelas que positivam "valores" e "direitos", como as que dispõem sobre direitos humanos e garantias fundamentais, e há aquelas que tratam de interesses econômicos internacionais, como os tratados sobre a dívida externa, sobre o direito do mar, direito aeronáutico $\mathrm{e}$, em princípio, os tratados de integração econômica e seus atos derivados ${ }^{17}$

Nesse sentido, a razão parece estar com o Ministro Rezek, quando afirma que a Constituição de 1988 não prestou maiores homenagens ao Direito Internacional Públi$\mathrm{co}$, a não ser àquelas que ele realmente merece, isto porque as regras do cenário internacional não estão totalmente fixadas e dependem ainda fortemente do poder econômico e da importância política de cada país. Não é, portanto, a origem internacional da norma, principalmente das normas que limitam direitos já conquistados, característica suficiente para determinar a sua justiça, como se um direito natural fosse, ou a sua adaptação - sem controles - ao sistema jurídico brasileiro ${ }^{19}$.

Mister, portanto, que se analise seriamente no Brasil, se concretizada e aceita a integração no MERCOSUL, da futura necessidade de uma modificação constitucional, a exemplo do que ocorreu na maioria dos países europeus. Estes, quando passaram a integrar a Comunidade Econômica Européia, introduziram em suas Constituições normas permitindo a eficácia imediata (e, neste sentido, monista) das leis obrigatórias formuladas pela Comunidade e norma prevendo a primazia, não de todas as regras de direito internacional público, mas sim do direito "comunitário", oriundo da atividade legisladora daquela instituição supranacional, legitimada para tal ${ }^{20}$.

Note-se que, mesmo nos países da Comunidade Européia, os Tribunais Constitucionais continuam a submeter o direito comunitário ao crivo de suas Constituições, em especial no que se refere à violação dos direitos fundamentais assegurados a seus cidadãos ${ }^{21}$. Mesmo hoje, mais de 30 anos após os Tratados instituidores das Comunidades Européias ${ }^{22}$, a proteção dos direitos fundamentais conquistados nas Constituições de mocráticas européias é considerada "campo de aplicação irredutível" do direito nacional $^{23}$.

Por todo o exposto, a origem constitucional do mandamento de proteção ao consumidor no Brasil concede ao Código como lei protetora, uma inegável força. Em caso de conflito do hoje disposto no CDC com a legislação eventualmente oriunda do legislador do MERCOSUL, a origem constitucional da lei brasileira poderá garanti sua manutenção pelo Judiciário brasileiro. A defesa do consumidor não é somente princípio da ordem econômica brasileira, mas é, especialmente, direito fundamental assegurado por nossa lei magna.

\section{CDC como norma de ordem pública}

Tendo em vista a origem constitucional do mandamento de defesa do consumidor ${ }^{24}$, não deve surpreender o fato de $o$ artigo $1^{\circ}$ do $C D C$ autodefinir suas normas, como normas de ordem pública. As normas de ordem pública são aquelas que positivam valores básicos de uma sociedade e, portanto, indisponíveis à vontade das partes.

A Constituição representa atualmente não só a norma máxima, mas o centro do próprio sistema do direito brasileiro ${ }^{25}$. Sendo assim,-lógico que a Constituição sirva o mesmo tempo como guardiã de seus princípios, como observamos no ponto antes analisado, e como centro irradiador das novas linhas mestras do ordenamento jurídico de um país. Essas linhas mestras propostas pela Constituição traduzem os princípios de ordem pública de um país, a influenciar a atuação do Legislativo, do Executivo e principalmente do poder Judiciário daquele país.

Face a esta nova força normativa da Constituiçãa ${ }^{26}$, o direito privado passa a sofrer uma influência direta da nova ordem pública, no caso ordem pública econômica, por ela imposta; muitas das relações particulares, antes deixadas ao arbítrio da vontade das partes, obtém relevância jurídica nova e conseqüente controle estatal rígido. As relações de consumo no mercado brasileiro e seu novo controle estatal através dos direitos e deveres positivados no Código de Defesa do Consumidor são exemplos claros deste fenômeno de "publicização do direito privado"27.

O caráter de norma de ordem pública de todas as regras do Código de Defesa do Consumidor representa um importante limite à autonomia privada, tanto em sua face econômica - a liberdade de iniciativa no mercado brasileiro (art. 170, V, da Constituição) ${ }^{28}$, como em sua face jurídica - a liberdade de contratar e a liberdade contratual de estabelecer o conteúdo destas relações, 
que envolvem fornecedores de produtos e serviços e consumidores no mercado brasileiro.

O caráter de ordem pública da norma em estudo é também importante porque destaca hierarquicamente. Também no Brasil, as antinomias entre as normas do sistema (por exemplo, normas civis e normas comerciais, normas especiais para determi nadas atividades econômicas e normas ge rais, leis especiais para determinados contratos, como leasing, locação, alienação fiduciária, contratos bancários etc., e regra gerais sobre contratos) resolvem-se com base nos três critérios clássicos: anteriorid de, especialidade e hierarquia. Sendo que, em caso de conflito entre critérios (lei gera posterior e lei especial anterior, por exemplo), a hierarquia pode ser o critério definidor usado pelo juiz. ${ }^{29}$

\section{Norma de interesse social}

Seguindo essa linha constitucional de nova função social do direito privado, esclarece o artigo $1^{\circ}$ do Código de Defesa do Consumidor que suas normas são "de interesse social".

Considerada supérflua para alguns, esta expressão ajuda a determinar a natureza das normas do CDC, as quais dispõem sobre matérias tão diferentes como direito civil, comercial, econômico, administrativo, processo civil e direito penal. Une-as a idéia básica de proteção de um grupo social debásica de proteção de um grupo social determinado, os consumidores, assim defin dos pela lei, considerados, em principio como vulneráveis na sociedade de massas

rias de direito civil tratadas pela nova lei, definição da presença do interesse social ajuda a atuação do aplicador da lei, no sentido de garantir eficácia às novas normas. Para estabelecer novos limites a princípios tradicionais como os da liberdade contratual e a liberdade de iniciativa dos fornecedores, a nova lei precisa declarar a sua própria natureza de interesse social. Assume, assim seu caráter de lei intervencionista, típica do Estado social, criada com a difícil tarefa de mudar uma realidade social, de estabelecer novos parâmetros de equilí brio e respeito na sociedade brasileira.

A expressão "interesse social" possui também uma outra finalidade específica no sistema do direito brasileiro e que merece se mencionada. Trata-se de uma antiga polêmi ca brasileira sobre a legitimação para a defesa dos interesses difusos.

A proteção jurídica destes interesses de massa ou interesses transindividuais ${ }^{31}$, em um país com tantas desigualdades econômicas e com níveis de formação tão diferenciados em sua população, só se tornaria uma realidade com a modificação da regra sobre o acesso à justiça e o fim da passividade social frente aos abusos do poder econômico. Nesse sentido, a legitimação para agir na defesa dos interesses foi concedida não só para associações da sociedade civil organizada, mas também para órgãos estatais específicos (art. 82 do CDC).

Dentre os órgãos estatais, destaca-se a participação do Ministério Público, fiscal da lei e novo Ombudsman do Mercado de Consumo brasileiro. Nesse sentido, a menção no artigo $1^{\circ}$ do CDC da expressão "interesse social", pode facilitar a atuação do Ministério Público, pois o art. 127 da Constituição Federal de 1988 autoriza a sua atuação ampla (administrativa e judicial) para: "a defesa da ordem jurídica, do regime democrático e dos interesses sociais e individuais indisponíveis".

Face a estas observações, podemos concluir que se a expressão utilizada no artigo 1o do CDC não tem a força e a tradição da idéia de ordem pública, a decisão do legislador foi sábia, pois, preservando o caráter público ou privado da norma de conduta, definiu de maneira geral e indiscutível o interesse social que as acompanha, hierarquizando-as.

\section{B) Conteúdo da nova lei protetora}

Verificada a natureza da nova lei, sua importância hierárquica e fática no sistema do ordenamento jurídico brasileiro, cabe agora examinar o conteúdo desse novo Có- digo. Muito já foi escrito sobre o aporte do $\mathrm{CDC}$ ao direito brasileiro, especialmente ao direito das obrigações e ao direito processual civil ${ }^{32}$, motivo pelo qual gostaríamo aqui de mencionar apenas seus aspectos básicos e de maior repercussão para uma futura integração.

Mister que se inicie analisando o artigo $4^{\circ}$ do CDC, regra-chave na interpretação e no entendimento da nova lei. No art. $4^{\circ}$ do CDC, positivou o legislador os objetivos que animam a nova lei, esclarecendo assim a ratio das normas do próprio CDC. A regular a "política nacional de relações de consumo", determinou a própria interpretação teleológica de suas normas. O art. $4^{\circ}$ é, portanto, uma norma que indica o resultado a ser alcançado pela política de proteção ao consumidor, política que inclui e se materializa nas regras do CDC. Trata-se assim de uma verdadeira "norma-objetivo", n classificação do mestre de São Paulo.

No art. $4^{\circ}$ do CDC, podemos observar que a atuação do Estado brasileiro nesta matéria objetiva "o atendimento das necessidades dos consumidores, o respeito à sua dignidade, saúde e segurança, a proteção de seus interesses econômicos, a melhoria de sua qualidade de vida, bem como a transparência e harmonia das relações de consumo".

São esses os objetivos que autorizam uma atuação estatal controladora, especificada nos cento e poucos artigos do CDC Esta atuação é conduzida tendo por base guiada por alguns princípios também especificados no art. $4^{\circ}$ do $\mathrm{CDC}$, quais sejam: princípio da vulnerabilidade do consum dor (art. 4, I) ${ }^{34}$, o da obrigação da ação governamental para a proteção do consum dor $\left(\right.$ art. 4, II) ${ }^{35}$, o princípio da boa-fé equilíbrio nas relações entre fornecedor consumidor (art. 4, III) ${ }^{36}$, o da facilitação do acesso à justiça (art. 4, V ) ) $^{37}$ o da repressão aos abusos e à concorrência desleal $^{38}$ no mercado (art. 4,VI)

Por sua vez, o CDC garante novos direito básicos ao consumidor, oriundos de seu dire to fundamental de proteção, assegurado pela Constituição (art. 5을 inciso XXXII). A meto- dologia escolhida pelo CDC foi a de assegurar direitos a um grupo de indivíduos, os consumidores, em seus artigos $6^{\circ}$ e $7^{\circ}$, e impor em todo o corpo do texto deveres a um outro grupo social específico, os fornecedores de produtos e serviços, e ao próprio Estado e seus órgãos de atuação. Nesse sentido, analisar os direitos assegurados ao consumidor é analisar o espírito do texto do $C D C$, pois os artigos que seguem a declaração de direitos dos arts. $6^{\circ}$ e $7^{\circ}$ nada mais fazem do que positivar linhas de conduta no mercado, as quais visam justamente a efetivar e assegurar o cumprimento destes novos direitos.

Os direitos assegurados ao consumidor pelo art. $6^{\circ}$ do CDC são: a) proteção à vida à segurança, instituindo assim uma proteção contra os riscos da sociedade de consumo, especialmente no que se refere aos danos causados por produtos e serviços defeituosos e regras especiais sobre o fornecimento de produtos perigosos (art. 6⿳⺈, I); b) proteção da liberdade de escolha e da igualdade nas contratações, tanto através do direito à educação, quanto do novo direito à informação, como da proteção contra publicidade enganosa ou abusiva, contra práticas comerciais abusivas (art. 6o, II, III e IV); c) proteção do equilíbrio das relações contratuais de consumo, através do controle e proibição de cláusulas abusivas e da nova possibilidade de modificação judicial de algumas cláusulas (art. 6o ${ }^{\circ}$ IV e V); d) direito à efetiva reparação e à prevenção dos danos patrimoniais e morais, assim como danos individuais, coletivos e difusos; e) proteção administrativa e processual eficaz, através da facilitação do acesso à justiça e da realização da prova em questões de consumo, inclusive com a possibilidade de inversão do ônus da prova pelo juiz, assim como a prevenção ou a reparação dos danos pela atuação conciliatória administrativa $e$ pela prestação adequada e eficaz dos serviços públicos (art. 6을 VII e VIII).

Interessante observar ainda que o art. $7^{\circ}$ do CDC é um fator de abertura do sistema brasileiro positivado de proteção ao consumidor, pois afirma que: "Os direitos previs- 
tos neste Código não excluem outros decorrentes de tratados ou convenções internacionais de que o Brasil seja signatário, da legislação interna ordinária, de régulamentos expedidos pelas autoridades administrativas com petentes, bem como dos que derivem dos princípios gerais do direito, analogia, costumes e eqüidade." (grifo nosso)

Sendo assim, os direitos assegurados pelo Tratado de Assunção e outros tratados $\mathrm{e}$ atos internacionais elaborados com vistas à integração do MERCOSUL, se direitos garantidos ao consumidor, passarão - ex lege - a integrar o sistema do CDC de proteção ao consumidor, como por exemplo a gratuidade prevista no Protocolo de Las Leñas de Cooperação e Assistência Jurisdicional, assinado pelos quatro países em 27 de junho de $1992 . .^{40}$ Parece-nos, face ao objetivo comum em ambos os textos legais, qual seja o da melhoria da qualidade de vida dos indivíduos, possível que o MERCOSUL, seguindo o modelo deixado pela Comunidade Econômica Européia, torne-se um grande legislador para a proteção dos interesses do consumidor; reconhecendo, assim, que os atores da integração não são somente os Estados e os empresários que importam e exportam, mas os consumidores que aceitam e consumem estes produtos em todos os quatro mercados nacionais integrados.

A compatibilização da lei brasileira com os objetivos do MERCOSUL seria, pois, a solução ideal, onde a lei brasileira assumiria seu papel de norma fundamental tuteladora dos interesses sociais e econômicos dos cidadãos no MERCOSUL, e o nível de proteção já atingido seria mantido e estendido aos outros mercados e indivíduos. Será esta, porém, a visão que prevalecerá?

\section{O Código Brasileiro de Defesa do}

Consumidor como lei limitadora
ao livre comércio no MERCOSUL

Como observamos anteriormente, a legislação brasileira de proteção ao consumidor pode ser vista também como uma barreira à livre circulação de mercadorias e serviços entre os quatro países do MERCOSUL, liberdade esta básica para o sucesso do processo de integração. Para que se possa concluir pela caracterização do CDC como lei discriminatória e limitadora do comércio não basta apenas um exame fático, é necessário que se realize um exame da nova lei frente ao "quadro" jurídico-econômico da integração proposta; do permitido e do proibido neste processo, das regras estabelecidas e impostas pelos Estados durante a criação e efetivação deste processo de integração de mercados e sociedades. Nesse sentido, cabe analisar a verdadeira caracterização da lei frente ao ideal integracionista proposto e os esforços atuais, seja para manter os direitos conquistados, seja para substituí-los por uma legislação harmonizada e média para os quatro países do MERCOSUL.

\section{A) $O C D C$ como barreira não-tarifária}

Visando a estabelecer a livre circulação de bens, serviços e fatores produtivos (art. 1 do Tratado), o MERCOSUL deve necessariamente preocupar-se com a eliminação das barreiras ao livre comércio entre os seus países. Não se trata apenas de barreiras físicas (fronteiras), mas de barreiras jurídicas, entre as quais destacam-se os tributos ou direitos alfandegários, que possuem como função, por excelência, impedir ou dificultar a entrada de produtos estrangeiros no mercado nacional, protegendo assim o produtor e a indústria local.

A eliminação dos direitos alfandegários ("a tarifa 0\%") entre os quatro países é um dos objetivos que o MERCOSUL pretende atingir até 31 de dezembro de 1994 (artigo $3^{\circ}$ do Programa de Liberação Comercial, Anexo I do Tratado de Assunção, enquanto o art. $7^{0}$ prevê prazos especiais para Paraguai e Uruguai). $\mathrm{O}$ art. $1^{\circ}$ do Tratado de Assunção menciona, igualmente, como objetivo, a eliminação das "restrições-não-tarifárias à circulação de mercadorias de qualquer outra medida de efeito equivalente". ${ }^{41}$

Ora, a ampla legislação brasileira de proteção do consumidor caracteriza, faticamente, um novum, uma diferença marcante no mercado brasileiro em relação aos mercados que não possuem normas impondo tais níveis de qualidade, segurança e informação em relação aos produtos e serviços; mercados que não conhecem o novo equilíbrio obrigatório das relações contratuais de consumo, ou a facilidade no acesso à justiça, ou que desconhecem tal grau de responsabilização administrativa e penal pelas atividades abusivas dos fornecedores no mercado. A legislação brasileira representa, assim, faticamente, um fator de ponderação especial no caso da colocação de produtos e serviços estrangeiros no mercado brasileiro, pois estes, obrigatoriamente, terão de adaptar-se às exigências legais.

A idéia base da integraşão econômica é, porém, a de possibilitar a colocação do produto ou serviço estrangeiro (a entrada do capital ou do trabalhador estrangeiro...) nas mesmas condiçóes, no mesmo patamar concedido ao produto ou serviço nacional. É a idéia mestra do tratamento igualitário, da não-discriminação, da concorrência total e leal no novo mercado integrado ${ }^{42}$.

Não é idéia integracionista ou seu objetivo privilegiar o produto ou produtor estrangeiro frente aos "pares" nacionais, por exemplo, permitindo que coloque no mercado produtos sem a segurança, a informação em língua portuguesa e a qualidade mínima exigida para os "pares" nacionais

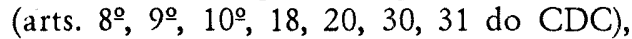
que utilize métodos de vendas proibidos para os "pares" nacionais (como a venda casada e a publicidade enganosa, por exemplo, proibidas nos arts. 39 , I, e 37 do CDC), que transfira todos os riscos do negócio para o consumidor, através de cláusulas contratuais unilaterais e abusivas, quando recorrer a tais cláusulas seria impossível para o fornecedor nacional (como as cláusulas abusivas consideradas nulas nas relações de consumo pelos arts. 51, 53, ou a responsabilidade indisponível pelo vício do produto e serviço dos arts. $18 \mathrm{ss}, 24$ e 25 do CDC).

Faticamente, portanto, o fornecedor argentino, uruguaio ou paraguaio que desejar colocar seus produtos no Brasil (e o impor- tador responsável) terão de adaptar-se às regras do mercado brasileiro quanto à proteção do consumidor e o respeito para com este. Estabelecerão, porém, estas regras, verdadeiramente, uma "barreira" à entrada destes produtos no mercado brasileiro, à liberdade de circulação de mercadorias no MERCOSUL?

Se definimos "barreira ou restrição" toda dificuldade ou standard imposto por um país, a resposta será necessariamente afirmativa, pois o CDC impõe efetivamente um novo patamar de conduta para os produtores de outros países não acostumados a estes níveis de qualidade ou segurança. Se definimos "barreira" àquele tratamento, fático ou jurídico, diferenciado para o estrangeiro, então o CDC não seria considerado como tal, pois, na verdade, trata-se de um novo patamar de boa-fé nas relações de consumo imposto a todos, nacionais e estrangeiros no mercado.

Se definimos "barreira" à circulação de mercadorias, ao aumento de custos para o produtor, no esforço de adaptar-se às exigências e a responsabilidades que não conhece de seu país de origem, então o CDC pode ser caracterizado como uma, pois acarretará, na prática, um aumento dos custos (seguros, contratos assegurando assistência técnica no Brasil, vendas de peças, novos deveres para o importador, etc.); tudo, é claro, se comparado em relação à colocação do produto no mercado original, que desconhece estas normas protetoras. Se definimos "barreira" como aquela que impede faticamente a entrada de um produto ou serviço, então o CDC não seria considerado como tal, pois não especifica quem pode prestar serviços no mercado brasileiro, ou quais os produtos que podem ser comercializados, sómente impõe responsabilidades e deveres de informação e de indenizar, caso estes produtos ou serviços não atinjam a qualidade (por vício ou por defeito) exigida; ou sejam comercializados através de práticas comerciais abusivas e proibidas no mercado.

Face a estas diversas definiçōes possíveis, - Tratado de Assunção optou por definir o 
que considera por "barreiras" proibidas, dispondo em seu art. $2^{\circ}$, Anexo I - Programa de Liberação Comercial, que se entenderá por "restrições" do art. 1ㅇ, "qualquer medida de caráter administrativo, financeiro, cambial ou de qualquer outra natureza, mediante a qual um Estado impesa ou dificulte, por decisão unilateral, o comércio recíproco."

Como observamos anteriormente, as regras do CDC sobre a responsabilidade do fornecedor pela falta ou falha na qualidade e segurança do produto ou serviço não "im pedem" o comércio recíproco, da mesma forma que as exigências de informação, e de respeito às legítimas expectativas do consumidor, quanto ao conteúdo do contrato e seu cumprimento, também não "impedem" a entrada de produtos importados, assim como as exigências de informação, em língua portuguesa, sobre os riscos e os componentes do produto não passam de novos desafios para a organização do profissional, que passa a atuar no mercado brasileiro.

De outro lado, alguns consideram que a normas protetoras dos consumidores presentes no CDC "dificultam" o comércio recíproco. São os defensores da aplicação exclusiva da regra do Estado de Origem. Se para o Estado de Origem o produto possui a qualidade e a segurança exigida, isto bastaria, não se podendo aplicar a ele regra do país de comercialização, ou se estaria "dificultando" seu acesso ao novo mercado. Note-se que se a regra da "origem" é uma regra mais pragmática, do que eficiente não encontra aplicação no que se refere às regras sobre responsabilidade (contratual extracontratual), regras que representam a quase totalidade das normas privatistas do CDC. Em caso de dano, aplica o sistema jurídico brasileiro a lei do lugar onde ocorreu o delito, e não a do país de origem do produto ou do fornecedor (art. $9^{\circ}$ da Lei de Introdução ao Código Civil).

As regras do CDC, como exigem do fornecedor uma adaptação aos novos standards e impõem novos deveres indisponíveis, no que se refere à informação, qualidade e segurança, representam, assim, uma "dificuldade-fática" extra para o fornecedor estran- geiro do MERCOSUL, logo devemos examiir com mais atenção a hipótese de serem consideradas como "restrições" (=dificuldades), definidas no art. $2^{\circ}, b$, do Anexo I. Neste caso, é necessário ter em vista o que dispõe a frase final do referido art. 2 , letra b. Segundo esta, "não estão compreendidas no mencionado conceito (de restriçōes) as medidas adotadas em virtude das situações previstas no art. 50 do Tratado de Montevideo de 1980".

$O$ referido art. 50 do Tratado de Montevideo, que instituiu a ALADI, dispõe:

"Nenhuma disposição do presente Tratado será interpretada como impedimento à adoção e ao cumprimento de medidas destinadas à:

a) proteção da moral pública;

b) aplicação de leis e regulamentos de segurança;

c)

d) proteção da vida e da saúde das pessoas, dos animais e dos vegetais;

e) .

f) proteção do patrimônio nacional de valor artístico, histórico ou arqueológico; ..."

Logo, examinando-se o art. 20 do Anexo I do Tratado de Assunção em conjunto com o disposto no art. 50 do Tratado da ALADI, conclui-se que as "restrições ao comércio recíproco" (=dificuldades), as quais se destinarem à "proteção da vida e da saúde das pessoas", não serão consideradas como "barreiras não-tarifárias", estando, portanto, permitidas no MERCOSUL.

Tratando-se de regras que regulam a responsabilidade dos agentes econômicos nas suas relações com os consumidores, muitas das regras do CDC referem-se, indiretamente, à proteção da vida e da segurança do consumidor (veja ponto $\mathrm{I}, \mathrm{B}$ ). O próprio art. $4^{\circ}$ do $\mathrm{CDC}$ menciona o respeito à dignidade, saúde e segurança do consumidor como seus objetivos básicos. O CDC, porém, regula também a proteção dos interesses econômicos do consumidor e impõe uma nova transparência e harmonia no mercado, conforme a boa-fé. Seriam todas as normas referentes a estas matérias consideradas "restrivas" e contrárias à integração?
Certos estavam os pais da Comunidade Econômica Européia que a instituíram através de um Tratado-Quadro direto e regulamentador, o qual, além de bem definir as regras do novo mercado integrado, já esclarecia a competência de cada um dos seus órgãos e criava, dentre todos, um Tribunal Judicial, independente e especializado, com o monopólio na interpretação dos Tratados e das regras necessárias à integração.

Assim, prevêem os artigos 30 e seguintes do Tratado de Roma a eliminação das restriçôes quantitativas à im portação, bem como de todas as medidas de efeito equivalente. O seu art. 36, porém, excepciona as "proibições ou restrições à importação, exportação ou trânsito, justificadas por razões de moralidade pública, ordem pública e segurança pública; de protesão da saúde e da vida das pessoas... Todavia, tais proibições ou restrições não devem constituir, nem um meio de discriminaşão, nem restrição dissimulada ao comércio entre os Estados-membros."

Frente a esta norma, o Tribunal de Justiça da Comunidade pôde estabelecer e desenvolver o princípio da não-discriminação, do tratamento igualitário de produtos, no famoso caso, Cassis de Dijon ${ }^{44}$, ao mesmo tempo que pôde considerar como não-violador do tratado as famosas normas alemãs sobre a proibição de cláusulas abusivas da Lei de 1976, ou a law inglesa sobre responsabilidade objetiva pelo defeito do produto. Não havendo discriminação, não há violacão a ser declarada pelo Tribunal, mas havendo diferenças e dificuldades criadas por regras legais, que possam influenciar as condições igualitárias de concorrência, há competência para a Comissão da Comunidade atuar ${ }^{45}$. A Comissão, que também é órgão autônomo, formado por servidores de carreira em números proporcionais aos países e às nacionalidades integrantes da Comunidade, atua legislando ${ }^{46}$ ou sugerindo leis-modelos (Diretivas) de forma a harmonizar as legislações, na medida necessária e sempre com a finalidade do bom funcionamento do mercado comum ${ }^{47}$.

Estas duas opçōes trazidas pela experiência européia podem ser muito úteis para a solução no MERCOSUL da desigualdade legislativa criada pela ampla legislação brasileira de defesa do consumidor, especialmente pelo CDC. Em primeiro lugar, a sábia conclusão do órgão competente para interpretar o direito comunitário, que tais normas tutelares não constituem verdadeira restrição ou medida de efeito equivalente; em segundo lugar, a conclusão do órgão executivo, que as diferenças legislativas podem causar alguma dificuldade ao comércio dentro do mercado e, conseqüentemente, diferenças no tratamento entre cidadãos $e$ empresas nos vários mercados nacionais, devendo este órgão executivo preocupar-se com a aproximação das legislações: a harmonização.

B) $O C D C$ como matéria a harmonizar

Uma vez que no MERCOSUL, até o momento, não possuímos um órgão verdadeiramente judicial no sentido da competência, da independência e isenção ${ }^{48}$, a eximplo do Tribunal de Justiça das Comunidades, caberá ao Judiciário nacional interpretar as normas do CDC e o seu eventual conflito com o disposto no Tratado de Assunção, caracterizando-o ou não como "medida restritiva". A tendência, neste caso, será provavelmentede acompanhar o exemplo europeu e de compatibilizar a aplicação das normas, não considerando o CDC brasileiro como uma "restrição" ao comércio, tendo em vista os objetivos que unem ambos os sistemas; optando o juiz brasileiro pela manutenção do texto protetivo nacional.

Quanto às possibilidades de harmonização das legislações nacionais, inicialmente é necessário observar que o processo de integração do MERCOSUL, tem-se caracterizado, até 'o momento, por uma certa falta de transparência nos trabalhos dos Subgrupos e do próprio órgão executor, o Grupo Mercado Comum ${ }^{49}$. Resta, mesmo assim, a perspectiva este órgão executor estar intentando esforços no sentido de oportunizar a harmonização da matéria de defesa do consumidor. 
Sabe-se que o Subgrupo no 10 , de Coordenação de Políticas Macro-econômicas, tem trabalhado no assunto e que em abri de 1993 instituiu uma "Comissão de Estudos de Direito do Consumidor". Da mesma forma, preocupa-se o Ministério da Justiça do Brasil com a possibilidade de uma futura atuação legislativa do Conselho do MER COSUL e tem repetido sua posição básica de não ceder quanto ao patamar de proteção já alcançado pelo CDC na defesa do direitos dos consumidores. Estaria optando, ao contrário, por estimular os outro três Estados para que também legislem sobre a matéria. Esta solução, proposta pelo Ministério da Justiça brasileiro, permitiria a manutenção da lei nacional, como lei protetora de direitos fundamentais, ao mesmo tempo em que prepararia os produtos do MERCOSUL para a competição em mercados dos países desenvolvidos, os quais também possuem rí idas legislaçōes protetoras na matéria.

Considerando, porém, a falta de informaçōes precisas sobre o avanço na matéria, cabe traçar, ainda que brevemente, um painel sobre o processo de harmonização legi lativo. Trata-se de um método de aproximação das legislações menos intenso que a unificação ${ }^{50}$; unificação significaria a ado ção do mesmo conteúdo normativo, objetivando, ao contrário, apenas a coordenação das diferenças existentes nos ordenamentos jurídicos nacionais. A harmonização se faz unificando somente algumas regras básicas e propondo normas acessórias para aquele Estados cuja legislação é mais tímida. As sim, o Estado que já possui legislação na matéria somente a adapta ao espírito das normas básicas propostas e, se impossível a adaptação, modifica o texto das normas. $O$ Estado que não possui legislação ou legislação em sentido contrário, legisla seguindo as linhas e muitas vezes as próprias palavras das normas básicas e secundárias propostas.

$\mathrm{Na}$ Comunidade Européia a harmonização é feita através de leis-modelo denominadas Diretivas (art. 189 do Tratado de Roma), obrigatórias para os Estados quanto a sua finalidade harmonizadora, mas dei xando-o livre quanto à forma, ao prazo e à extensão de sua "transformação em direito interno" ou sua inserção no ordenamento interno. Atualmente, por ação criadora interpretadora do Tribunal de Justiça da comunidades, as Diretivas têm o condão de ser obrigatórias, mesmo se não "transformadas" em lei interna; é a chamada incidência direta em caso de recusa do país de legislar segundo as linhas propostas pelas Diretivas $^{51}$. No MERCOSUL, a harmonização tem sido feita por Tratados Internacionais tradicionais ou por legislaçōes nacionais voluntariamente aproximadas, com base nas sugestões do Grupo Mercado Comum ${ }^{52}$ chamadas Resoluçôes ou das Decisões de Ministro. Não prevê o Tratado de Assunção nenhum mecanismo para a harmonização, nenhum instrumento para tal, somente sua realização e, ainda assim, voluntária (art. 1ำ do Tratado de Assunção).

Tendo em vista a incipiência deste processo no MERCOSUL, cabe aprender com a experiência européia. Também a da Comunidade Européia tornou-se uma das grandes legisladoras no tema da defesa do consumidor, para superar os reflexos da diferença legislativa na concorrência entre fornecedores do seu mercado. Se, porém, inicialmente sua tendência era de harmonizar amplamente, forçando a modificação das legislações nacionais de forma a atingirem todas um novo nível médio, hoje, como afirmamos anteriormente, sua ação legislativa evoluiu ${ }^{53}$, passando a exigir que os países sem legislação específica instituam-na, atingindo o nível médio, mas a permitir que os outros Estados mantenham níveis mais altos de proteção de seus cidadãos. São as chamadas "Diretivas minimais", que, além de permitirem a manutenção da legislação mais protetiva em vigor tendem a possuir um campo de aplicação pequeno, somente no estritamente necessário à formação do mercado comum ${ }^{54}$.

\section{Conclusão}

A primeira conclusão da análise realizada é a falta de uma estrutura jurídica sólida para o processo de integração, denominado
MERCOSUL. O "Mercado Comum do Sul" vem evoluindo, nesta fase de transição, como um fenômeno econômico e político voluntário, criando dúvidas sobre o seu caráter definitivo, face a sua incipiente obrigatoriedade jurídica, dúvidas sobre a eficiência prática de suas medidas e decisões, por contar apenas com os instrumentos tradicionais do direito internacional público, essencialmente pragmático e voluntarista.

No Brasil, pouco se atentou para a insegurança e a falta de credibilidade criadas por este descompasso consciente entre os sérios e complexos objetivos que o MERCOSUL se propõe a alcançar, e o que, faticamente, cada Estado-membro está comprometendo-se a fazer (obrigações) e a sujeitar-se (efetiva transferência de competências). ${ }^{55}$ Nesse sentido, necessário relembrar que a passividade da sociedade, atingida por este processo político e econômico de integração, pode tornar o que agora é "provisório" em "definitivo" e teremos perdido a oportunidade de instituir um sério e confiável processo de integração.

Paciência, mas também coragem! Se, em uma América Latina sem tradição de colaboração a longo prazo entre Estados, diríamos que já foi muito o alcançado pelo MERCOSUL, devemos ter também a coragem de transformar este "muito" em um verdadeiro "Mercado Comum". Esta não deve ser uma expressão ilusória, vazia de conteúdo e obrigatoriedade. Se assim denominamos o processo de integração destes quatro países, devemos então realiza-lo, criando bases sólidas, estruturas definitivas, instituições autônomas e transparentes, contando com instrumentos eficazes e democráticos, com competências estabelecidas e obrigatoriedade real, e não só baseada em conveniência nacional passageira ${ }^{56}$.

Um processo de integração (e não só colaboração) deve merecer a credibilidade do mercado, dos empresários (nos momentos de lucros, mas também nos de perda) dos consumidores, assim como dos aplicadores do direito (magistrados, advogados e membros do Ministério Público). Parece-nos que, na insegurança sobre o futuro da integração, a prioridade deve ser a de "construir" a estrutura jurídico-política reclama$\mathrm{da}$, de realizar e possibilitar faticamente a livre circulação de mercadorias e serviços no MERCOSUL, e não a de "destruir", de regredir nos avanços sociais e nas garantias já conquistadas.

A análise realizada evidenciou um real perigo de retrocesso jurídico, se, embuído do espírito econômico liberal do MERCOSUL, os governos envolvidos priorizarem a função econômica do direito e não sua função social, esquecendo-se dos verdadeiros atores da integração, pessoas físicas e jurídicas, fornecedores e consumidores, e do objetivo máximo do processo de integração, que é a melhoria da qualidade de vida dos indivíduos neste mercado integrado.

Coragem, para evoluir, mas evoluir socialmente, e não só economicamente. Nesse sentido, urge refletir com cuidado na agora pensada revisão constitucional e na reclamada necessidade de modificações na Constituição brasileira, para adequá-la ao MER COSUL. Nunca é demais relembrar distinção entre princípios e normas constitucionais. Se se pretende, no futuro, seguindo o modelo europeu, transferir alguma competência legislativa ou decisória (=soberania) para o MERCOSUL, necessária se fará a modificação do texto da Constituição, mas não de seus princípios.

$O$ processo de integração não conflita com os princípios constitucionais da soberania popular (art. 1\%, parágrafo único, da $\mathrm{CF} / 88$ ) e aos aqui referidos princípios do dualismo e da primazia da Constituição frente aos Atos internacionais. As norma constitucionais é que devem ser redigidas (ou interpretadas) de forma a permitir (ou autorizar) a evolução de um processo de integração sério e materialmente benéfico à sociedade. A imutabilidade dos princípios constitucionais constitui uma garantia básica, a segurança de uma sociedade e seu modo de vida. Também as normas constitucionais preenchem, de certa maneira, essa função de estabilidade do sistema. Sendo assim, talvez mais sábio de que modificá-las agora, seria fazê-lo a posteriori, concomitan- 
temente com os outros três países, através de Emendas Constitucionais específicas e
pontuais, quando o MERCOSUL realmente pontuais, quando o MERCOSUL realment necessitá-las, como processo definitivo que esperamos ${ }^{57}$.

Quanto a aqui levantada caracterização da lei brasileira como "restrição não-tarifá ria ao comércio", é esta de aceitação difícil no atual estágio de evolução do MERCOSUL. Tendo em vista, porém, as fáticas di ficuldades e diferenças por ela criadas, melhor seria se a competente Comissão ou Subgrupo trabalhasse no sentido de elaborar e sugerir, a exemplo da Comunidade Européia, uma harmonização minimal das normas tutelares dos consumidores no MERCOSUL, evitando, assim, as diferença legislativas atuais e a discriminação indiret dos produtos e consumidores dos outros três países.

Por fim, cabe esperar que o Direito poss assumir, também no âmbito do MERCO SUL, uma função mais efetiva, e que o Tratado, marco definitivo que está sendo preparado para o MERCOSUL, possa suprir as apontadas falhas atuais. Nesse sentido, esperamos, igualmente, que o Código Brasileiro de Defesa do Consumidor possa cum prir seu papel de lei protetora dos direitos fundamentais econômicos, de forma a alcançarmos todos, através de novas legislações em nossos países, um melhor nível de qualidade, de transparência, de lealdade e de competitividade no fornecimento de produtos e serviços no MERCOSUL.

julho 1993

\section{Notas}

1 O Tratado de Assunção, que é o Tratado-instituido do MERCOSUL e base única para a criação de deveres para os quatro Estados, foi ratificado pelo Brasil c
Argentina, em 30/10/91, c pelo Uruguai e Paraguai, em Argentina, em $30 / 10 / 91$, e pelo Uruguai e Paraguai, em
$1 / 8 / 91$, entrando em vigor no Brasil, em $22 / 11 / 91$, internacionalmente, em 29/11/91. Trata-se, porém, de um Tratado provisório e tímido, devendo ser substituído mento do Mercado Comum, em dezembro de 1994; mento do Mercado Comom, ell tezembro te 1994; Asunción y algunas cuestiones jurílicas que plantea", in: Rer" urídica del Centro Estudiantes de Derecho, Número Espe MERCOSUR (Nr. 5), Montevideo, 1991, pág. 10. $\mathrm{O}$ art. 1ำ do Tratado de Assunção prevê o "compro misso dos Estados-Partes de harmonizar suas legisla çoes, nas áreas pertinentes, para lograr o fortalecimento do processo de integração.", mas o texto do Tratado ão prevê instrumentos legislativos para tal. O MERCOSUL não tem competência para legislar, nem para impor "leis-modelos", como acontece na Comunidade Européia, tanto que no cone sul as harmonizaçoes têm contecido por Tratados Internacionais ou por publiÇôes das decisões e recomendações do Conselho ou Grupo do MERCOSUL nos Diârios Oficiais. Note-se, que, em principio, estas publicaçoes são sem nenhuu gislador do MERCOSUL passando estas "sugros de modificacões das leis internas e normas adminises ivas" a depender da boa vontade dos Poderes Exisu-

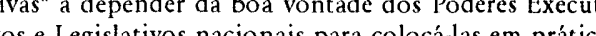

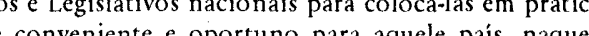
pás, naquele

3 Entre as instituições (ou órgãos) criados para gerir o MERCOSUL, não há nenhum órgão verdadeirament judicial, semelhante ao Tribunal de Justiça das Comu a cho européia, pois atraves de sua independéncia e forç duais do cidadao das Comunidades, quanto impor ines Estados-partes o cumprimento de seus deveres de inte raço. O MERCOSUL optou, ao contrário, por um sistema de solução de controvérsias menos vipor un independente, regulado no Protocolo de Brasília, de 7.12.91, que insitui, Arbitral ad boc".

${ }^{4} \mathrm{O}$ problema aqui levantado é o da eficácia do sistema criado pelo Protocolo de Bráasília para as reclamações das pessoas físicas e jurídicas envolvidas no MERCO dura, problema que será examinado

${ }^{5}$ Assim conclui tb. Abreu Bonilla, Sérgio "Mercosur Integración", FCU, Montevideo, 1991, pág. 56.

6 Dado estatístico, referente a 1990, fornecido po Amorin, Celso Luiz Nunes, "O Mercado Comum do Sul e o Contexto Hemisferico", in: Boletim de Diplomacia Econômica, nr. 7, Secretaria-Geral de Política Exterior 1990, pág. 17.

${ }^{7}$ Note-se que até esta data o MERCOSUL funcionará como uma Zona de Livre Comércio, como prevéem o constituir um "Mercado Comum", o que significa nas só a formação de um bloco económico de atuaça unica, com uma Tarifa Externa Comum e coordenaça das políticas macroeconômicas, mas também a concre ização da ampla liberdade de circulaçăo de mercadorass, serviços, pessoas e capitais.

${ }^{8}$ A esta conclusão chegou tb. naturalmente a Comuidade Econômica Européia, e é de seu primeiro Pre- econômica, mas uma comunidade de direito", no original: "eine Recblsgemeiscbafi", como ensina MüllerGraff, Peter-Christian, "Europäisches Gemeiscbafi und Privatrecht", in: NJW, 1993, pág. 17.

9 Apesar de dificuldades quanto a sua legitimidade para elaborar diretivas (leis-modelo obrigatórias) na matéria, a Comissão da Comunidade Européia, alegando que os temas de defesa do consumidor eram os mesmos que assegurariam uma concorrência leal entre os empresários de seus doze países, elaborou mais de 20 diretivas na matéria, sendo as mais famosas: Directiva 450/84 (Publicidade enganosa), 374/85 (Responsabilidade derivada de Produto Defeituoso), 577/85 (Contratos negociados fora do estabelecimento comercial), 102/87 (Crétito ao consumo), 324/90 (Contratos de viagens e ferias), $81 / 93$ (Cláusulas abusivas); veja completo artigo de Garcia-Cruces, J.A. Gonzales, "Da

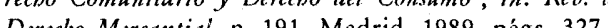
Derecbo Mercantial, n. 191, Madrid, 1989, págs. 327

${ }^{10}$ Sobre as modificações na ação legisladora da comu nidade Européia veja os artigos de Schmidhuber/Hitlzer, "Binnemarkt und Subsidiaritätsprinzip", in: EuZW 1/1993, pág. 8 e Goppel, T. "Die Bedeutung des Subsis diaritätsprinzips", in: EuZW 12/1993, págs. 367 e segs. quanto ao reflexo do novo Princípio da Subsidiaridade guiando a competência e a interpretação do direito comunitário em matéria de proteção do consumidor, veja de Micklitz e Reich, "Verbraucherscbutz im Vertrag über die Europäiscbe Union - Perspektiven für 1993", in EuZW 19/1992, págs. 593 e segs.

${ }^{11}$ São as chamadas Diretivas minimais, como a última diretiva sobre cláusulas abusivas, que institui uma proteção mínima para o cidadão da Europa, mas permite que a lei alemã de 1976, por exemplo, continue em vigor e estipule uma lista mais rigorosa de cláusulas ineficazes, isto porque não há prejuízo verdadeiro ao mercado comum em uma proteção econômica maio do consumidor de um determinado pais; assim conclui tb. Ulmer, Peter, "Zur Anpassung des AGB-Gesetzes an dic EG-Ricbllinie über missbräucblicbe Klauseln in Verbraucberverträgen", in: EuZW 11/1993, págs. 337 a 346.

12 Assim ensina o Professor de Montevideo, Jean Michel Arrighi, em seu excelente artigo, "La Protectión de los Consumidores y el Mercosur". in: Revista Direito do Consumidor, vol. 2, pág. 134; sobre as modificaçōes na Argentina, veja o amplo e comparativo levantamento dos Projetos existentes feito por Alterini, A.A. e Lopez Cabana, R.M., "Proyectos de Ley de Defensa del consumidor en la Argentina", in: Rervista de Direito Civil, $\mathrm{n}^{\circ} 56$, págs 231 e segs., passado um mês da aprovação, com vário vetos, da lei argentina, ainda é cedo para verificar da eficácia da nova lei, veja Stiglitz, G.A., "O Direito do Consumidor e as Práticas Abusinas - Realidade e Perspectivas na Argentina", in: Revista de Direito do Consumidor. vol. 3, págs. 27 e segs.

13 Sobre o tema, veja as liçōes dos mestres de São Paulo, Konder Comparato F "Ordem Econômica na Constituisãa Brasileira de 1988", in: RDP 98 (1990), 271, e Grau, Eros Roberto, "A Ordem Econômica na Constituişão de 1988 - Interpretaşão e Crítica", São Paulo: Revista dos Tribunais, 1991.

${ }^{14}$ Assim decisão do Supremo Tribunal Federal, em 27 de fevereiro de 1987, no RE 0109173/SP, citando vários precedentes; em doutrina, veja os comentário clássicos de Tenório, Oscar, "Lei de Introduşão ao Código Civil Brasileiro", Rio de Janeiro: Borsói, 1955, pág. 86 - 129; esta tambèm é a tendencia internacional (pre -integraçáo economica), como ensina Paul De Visscher, em seu curso na Academia de Haia, "Les Tendanas Internationales des Constitutions Modernes", in: Recueil

15 Veja a polêmica exigindo também o controle do legislativo aos tratados internacionais, especialmente quanto aos Tratados chamados executorios e os atos que estabeleceram a divida externa brasileira, sua for ma de Medeiros, A.P., "O controle legislativo dos atos interna cionais"; sobre a relação do Tratado e da lei interna veja Fillipi, R.B., "Conflito entre Tralado Internacional e Lei interna posterior no tempo", in: Revista AJURIS, vol. 34 págs. 226 e segs.

${ }^{16}$ No Brasil, defende um quase "monismo" baseado neste texto constitucional, Bastos, Celso Ribeiro, in "Comentários à Constituigão Federal de 1988", 1988, v. 2 17 Defendendo a necessária "valoração" das normas de origem internacional para a boa aplicação do art. $5^{\circ}$ $\S 2^{\circ}$, da CF, veja o nosso " $A$ Responsabilidade do Trans portador Aéreo pelo Fato do Servigo e o Código de Defesa do Consumidor", in: Rev. Direito do Consumidor, vol. 3, pág. 162

18 In: "Interpretaşôes da Constituição Federal de 1988", Ives Gandra Martins (Coord.), FUB, Brasilia, 1988, pág. 7.

${ }^{19}$ Nesse sentido já nos manifestamos no citado artigo "A Responsabilidade do Transportador Aéreo...", pág. 165. ${ }^{20}$ Veja o sério estudo realizado na Suíça, quando esta - antes do plebiscito de $1992 \cdot$ pretendia passar a inte-
grar o Mercado Comum, Cottier, Bertil (Coord.), "Con séquences institucionelles de l'appartenece aux Communautés Européennes", Publications de l'Institut Suisse de Droil problemas constitucionais originados pela adesão ao prógs. 19s, 57s, 77s, 155s, 189s, 223s, 257s, 287s, 325s págs. $19 \mathrm{~s}, 57 \mathrm{~s}, 77 \mathrm{~s}, 155 \mathrm{~s}, 189 \mathrm{~s}, 223 \mathrm{~s}, 257 \mathrm{~s}, 287 \mathrm{~s}, 325 \mathrm{~s}$ bros, nove tiveram de modificar sua ordem constitucional, pág. 411

${ }^{21}$ Veja o exemplo alemão, em suas famosas sentenças "So lange I" e "So lange II", em que o "BVerfG" (Corte

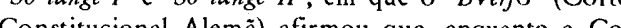
munidade na possíse uma Constiticio, assegurase os mesmos diretos fundamentis assegurados nurase

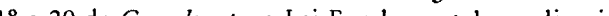
mesmo contra o direito da integracão, de forma lores básicos já conquistados; veja em Schwizer, M. e Hummer, W. "Europarth", Metzo Frankfurt, 1990, págs. 215 e segs. 
22 A comunidade européia é formada por três Comunidades, a do Carvão e do Aço (Tratado de Paris, de 18 abril de 1951), a Comunidade Econômica ou Mercado Comum (Tratado de Roma, de 25 de março de 1957) e a Comunidade da Energia Atômica ou Euraton (Tratado de Roma de 25 de março de 1957), veja interessante comparação de POCAR, Fausto, "Modelos de Integraşão regional na Europa e na América Latina e papel das integraģóes reggionais", págs. $9 \mathrm{e} \mathrm{segs.} \mathrm{do} \mathrm{número}$ especial dedicado à integração da Revista de Inform cão Legislativa, no 84, jan/mar 1984

23 a expressão é trazida por Von Simson, W. e Schwarze, J. "Europäiscbe Integration und Grundgesetz", de Gruyter, Berlin, 1992, pág. 65, obra que dá especial ae Gruyter, Berlin, 1922 , pág. 65 , obra que da especial atençà tado de Maastricht, o qual propõe a criação de uma comunidade monetária entre aqueles páses de uma maior integração política, o que naturalmente significa maior transferência de competências (ou soberania) para a Comunidade.

${ }^{24} \mathrm{O}$ art. 48 das Disposições Transitórias concedia 120 dias para que o Parlamento elaborasse o "Código Defesa e Proteção do Consumidor".

${ }^{5}$ Como ensina Amaral, F. dos Santos Neto, "A Liber dade de Iniciativa Econômica - Fundamento, Natureza Garantia Consitucional, in: Revista de Direito Civil, vol. 37, pág. 96, a noção de sistema pode ser útil nalise, pois "permite que o fenomeno juridico, à melhança do que vem sendo feito no âmbito das mais ciências sociais, seja apreciado como um conjun harmônico, unitário, coerente de normas jurídicas, constituído em função de valores e principios emergentes da realidade social... . Este conjunto coerente ser um todo construído, com uma hierarquia própria, com um encadeamento lógico, a determinar que seus valores e conceitos estivessem presentes e eficazes, nào $\mathrm{em}$ um só ramo do direito, mas em todo o ordename to jurídico de um país.

${ }^{26}$ Veja a famosa aula de Hesse, Konrad, " $A$ For Normativa da Constitui $\tilde{c} a$ ", trad. Gilmar Mendes, Porto Alegre, ed. Fabris, 1992.

${ }^{27}$ A expressão é de Raizer, Ludwig, "O futuro do Direito Privado", in: Revista da Procuradoria-Geral do Estado Porto Alegre, 9(25), 1979, pág. 11.

${ }^{28}$ Konder Comparato, ob. cit., pág. 263 , afirma que a defesa do consumidor foi erigida a princípio limitado da atividade econômica pelo art. 170, V, da Constituicão Federal.

${ }^{29}$ Nesse sentido a opinião de Bobbio, Norberto, "Des critéres pour résoudre les antinomies", in: Les Almomies Droit, Perelman, Ch. (Ed.), Bruxelas, 1965, pág. 255, assim também nos manifestamos em " $A$ Responsabilita de do Transportador Aéreo", ob. cit., págs. 167/168.

30 "Código" significa a criação de um sistema de regras de direito, ordenadas e unidas pela lógica de uma idéia central orientadora; veja as definições trazidas pelo mestre de Heidelberg, Jayme, Erik, "Considérations bis toriques el actuelles sur la codification du Droit Internatio- al Privê", in: Recueil des Cours de l'Academie de la Haye, 177 (1982, IV), pág. 23

A expressão é trazida por Watanabe, Kazuo, pág. 9, in: "Codigo Brasileiro de Defesa do Consunidor Co. nover et al. Rio de Janeiro: Forense Universitária

32 Veja o nosso livro, "Contratos no Código de Defesa do Consumidor - o novo regime das relaşốs contratuais", São ulo: Editora Revista dos Tribunais, 1992 e o antes itado Comentário dos Autores.

33 Assim ensina Grau, Eros, "Interpretando o Código de Defesa do Consumidor: Algumas Notas", in: Revista Dire to do Consumidor, vol, 5, pág. 185.

34 A presunção de vulnerabilidade do consumidor rente ao fornecedor guiará os três artigos do CDC que se referem à definição de consumidor, artigos $2^{\circ}, 17$ 29. O consu midor stricto sensu é a pessoa fisica ou juridica que adquire ou utiliza produto ou serviço, como desinatário final (art. $2^{2}$, caput), equiparando-se a ele to das as vítimas do dano causado por fato do produto ou do serviço (art. 17), a coletividade de pessoas, aind que indetermináveis, que haja intervindo nas relaçōes de consumo (art. $2 \stackrel{0}{ }, \S$ único), ou que fique exposta às práticas comerciais definidas no CDC (art. 29).

35 Este princípio guia a atuação ativa do Poder Execu. ivo, através de seus órgãos de proteção do Consumidor, de controle de preços e da saúde pública, bem omo a atuação no campo jurídico do Estado (art. $5^{\circ}$ ), através da criação de Juizados de Pequenas Causas, Varas Especializadas na Defesa do Consumidor, Promotorias, Assistência Jurídica Gratuita, etc. Sobre a base legal da atuação administrativa, veja o recente Decreto ํㅡ 861, de 9 de junho de 1993 (D.O.U. 2/08/93, Seção I, pág. 9551s), o qual dispōe sobre a organização do Sistema Nacional de Defesa do Consumidor-SNDC e estabelece normas gerais de aplicação das sanções administrativas.

${ }^{36}$ Este princípio serve de base para a imposição do dever de informar dos arts. 30 e seguintes do CDC, da transparencia e informaçăo quando da redação dos contratos unilateralmente (arts. 36 e 54), para a proibiça das praticas comercials abusivas descritas nos rts. 29 e seguintes, para a declachao da mulidade

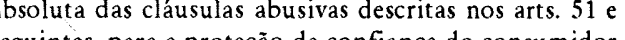
on dispostab nos ats 18 e seguina dos produtos e serviços, dispostas nos arts. 18 e seguintes e arts. 12 e seguintes do CDC, serve de base, inclusive, para a decretaça forne 37 Este é o princípio norteador das normas processuais trazidas pelo $\mathrm{CDC}$ em complementação à lei da ação civil pública de 1985, nos arts. 81 a 108 .

38 Este é o menos desenvolvido dos princípios no corpo do $\mathrm{CDC}$, talvez face às múltiplas e ineficazes normas brasileiras já existentes sobre regulamentação da concorrência.
39 Sobre o tema, veja também o excelente artigo de Nery, Nelson Jr., "Os Princípios Gerais do Código Brasileiro de Defesa do Consumidor", in: Revista de Direito idor, vol. 3, págs. 44 e seguintes.

40 O Protocolo foi objeto da MERCOSUL/CMC/DEC no 05/92, art. 15, veja sobre a Convenção de Bruxelas, ato semelhante entre os paises da Comunidade Européia, em Reich, Norbert, 'Protection of consumers' economic interests by European Community, in: Journal of Behavioral and Social Sciences, vol. 38, 1992, Japão, págs. 33 e seguinte.

Interessante notar que $\mathrm{o}$ art. $1^{\circ}$ nada menciona sobre as restrições à livre circulação de serviços. Se esta foi uma omissão consciente e quais serão suas consequiências práticas, não cabe aqui analisar em detalhes. Op. tamos, no texto, a mencionar a regulamentação dos produtos e serviços como trazida no CDC brasileiro, isto é, tratando-os igualmente.

${ }^{42}$ Assim ensinam os mestre alemães Schweizer/Hummer, ob. cit., págs. 269 e seguintes.

${ }^{43}$ Texto reproduzido na íntegra, in: Rev. de Informasão Legislativa, a. $21, \mathrm{n}^{\circ} 81$ - Suplemento, pág. 270

44 No famoso caso Cassis de Dijon (Rs. 120/78, Rern v. Bundesmonopolverveallung für Brandweein) Rspr. 1979 pag. 662, institulu o Tribunal de Justiça da Comun dade Européia a chamada "Regra-Cassis", a qual exc das medidas equivalentes as medidas e regras jurídic estabelecidas por um Estado, se razoaveis e necessár para uma efetiva proteção do consumidor, para a concorrência leal, para a proteção da saúde publica e para o controle do pagamento de impostos; veja senten reproduzida por Schweizer/Hummer, ob. cit., pág

45 Assim concorda, quanto aos objetivos da Comun dade e do Direito comunitário, a obra tradicional Cartou, Louis, "Communautés Européennes", Dalloz 1979 , pág. 142

$46 \mathrm{O}$ verdadeiro legislador stricto sensu da CEE é o Conselho, que promulga as leis obrigatórias da Co nidade, os "Regulamentos". Engana-se quem pensam o "Parlamento" das Comunidades tem função legislativa, pois este órgão, único escolhido de maneira democrática na $\mathrm{CEE}$, possui somente função consultiva, decidir o orçamento da Comunidade e um pequen poder de veto das leis elaboradas pela Comissão e pelo Conselho, que pode ser derrubado pelo Conselho Ministros; veja o art. 189 do Tratado de Roma. Eis aqui uma das fontes de critica quanto à legitimação (demo crática) da Comunidade Européia para legislar, veja de talhes em Rabe, Hans-]ürgen, "Europäiscbe Gesetzgebung das unbekannte Wesen", in: NJW 1993, págs. 1 a 5.

${ }^{47}$ Sobre a atividade administrativa, de controle e como elaboradora das leis, regulamentos e diretivas da $\mathrm{Co}$ munidade, pela Comissão, veja Schweizer/Hummer, ob. cit., pág. 79 .

48 O Protocolo de Brasilia estabelece um procedimento rbitral específico, o que garantirá certa isenção do arbitros, um de cada país envolvido e um terceiro escolhido; o problema central, porém, é a falta de obrigatoriedade do Estado enviar a queixa do em presá ro de seu pais (art. 27) e a não-adaptação do complexo procedimento de "tentativas de conciliąaao" entre órgăos nacionais do executivo com as necessidades das ares particulares. Se este procedimento representa um vanç̧o no que se refere às relações entre Estados latino-americanos, pouco acostumados às arbitragens, para os particulares não oferece o Protocolo de Brasília nenhuma segurança e perspectiva.

49 Para a crítica do sistema adotado pelo MERCOSUL, com a criação de um "Grupo", formado por servidores diplomatas dos ministérios nacionais, reunidos esporadicamente e sem nenhum poder de decisão (necessitando sempre da aceitação do Ministro de Estado, seu superior e do Presidente da República), veja o novo artigo de Baptista, Luis Olavo "O Impacto do MERCOSUL sobre o Sistema Legislativo Brasileiro", in: Revista dos Tribunais, vol. 690, págs. 39 e seguintes.

${ }^{50}$ Assim ensina nosso mestre alemão Will, Michael R., "Autonome Rechtsangleichung in Europa", in: "Osterreichs Weg in die $E G^{\prime \prime}$, Fritz Schwind (Hrsg), V.Oakw, Viena, 1991 , pág. 88.

${ }^{5} \mathrm{O}$ processo de incidência direta das Diretivas é complexo, deve o Estado já ter esgotado o prazo para directiva "er suçáo" em lei nacional e deve o texto da possibilitar que os cida da dire, de forma a pecorrer; sobre a culadaos da Europa possam a eles bunal de Justica das coma juisprud vesa do Trir/Humer, ob. cit. pas 115 .

52 Segundo a lição de Will, ob. cit., págs. 73 e seguintes, seria este tipo de harmonizaçăo denominado "har-

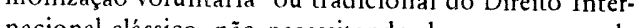
nacional clássico, não necessitando de um processo de integração económico para nascer, bastando a simples

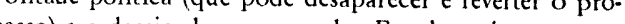
cesso) e o desejo de cooperar dos Estados soberanos.

Veja por todos, o citado artigo de Garcia-Cruces, e 8 e 9.

${ }^{4} \mathrm{O}$ art. $8^{\circ}$ da Diretiva adotada em 5 de abril de 1993 (JOCE-L de 21 de abril de 1993) dispõe que: "...os Estados-membros podem adotar ou manter...disposiçōes mais estritas, compativeis com o Tratado, para assegurar um nível de proteção mais elevado ao consumidor" (tradução nossa), texto reproduzido por Chambraud, A. "Les Cluuses abusins en droit camo por Chambraud, HEBDO, Nr. 820, 25 juin 1993, pág. 9.

55 Assim também Baptista, ob. cit., pág. 39, que diplomaticamente afirma: "O pragmatismo refletido na transitoriedade das estruturas criadas, e na leveza de tas, assim como o ter-se evitado criar mais uma buro-

6 Do ponto de vista jurídico, importantíssima seria a criação de um órgão verdadeiramente judicial, ou no minimo da melhoria do sistema arbitral/voluntario previsto, veja sobre a importante função do Tribuna 
da Comunidade no desenvolvimento e no grau de justiça alcançado com o diretito comunitário Nessler, págs. 206 e seguintes.

57 Note-se que a modificação das normas constitucioomplexo, pois enquanto várias delas (arts. 171, 172,
$73,176,177,179$, por exemplo) discriminam o capital estrangeiro, estabelecendo privilégios e monopólios as pessoas jurídicas nacionais de capital nacional ou pesas jurídicas de direito público, o governo brasileiro O-Brasileiras, tentando atingir um tratamento igualitário.

\section{As contribuições especiais na Constituição de 1988}

\section{Rômulo Maya}

Professor da UFRGS

Vice-Presidente do Tribunal Administrativo de

Recursos Fiscais do Rio Grande do Sul

As contribuições especiais são antigas no Brasil. Desde 1923, a Lei Eloy Chaves, criando a Caixa de Aposentadoria e Pensões dos Ferroviários, as instituiu. No mesmo ano, por força da Lei $n^{\circ}$ 5.109, aquele regime previdenciário foi estendido aos marítimos. A partir de 1934, com a criação da previdência social das demais categorias profissionais, através dos IAPs (Bancários, Comerciários, Industriários, etc), elas começam a proliferar. Em 1943, a CLT estabeleceu, nos arts. 578 e seguintes, o "imposto sindical", mais tarde acertadamente transformado pelo art. 217 do CTN em contribuição sindical. Daí em diante, principalmente a partir da década de 60, avolumaram-se as contribuiçōes especiais, também chamadas de parafiscais, em nosso país, estendendo-se a outros setores de atividade, tais como, por exemplo, o de intervenção da União no domínio econômico.

2. - Apesar da intensidade do fenômeno e de sua grande repercussão na própria vida nacional, as contribuições especiais não tinham sido objeto de ordenamento individualizado por parte de nossos constituintes. As Constituições de 34, 37, 46 e 67 delas não cogitaram expressamente, não obstante a elas se referissem quando versaram a previdência social. Só a Emenda nº 1, de 1969 , preocupou-se em outorgar às contribuições parafiscais a condição de figura constitucional.

3. - Como é sabido, a Lei Maior de 69 , em sua redação original, no art. $21-\S 2^{\circ}$ I, atribuiu à União a exclusividade para instituir contribuições, nos seguintes ter mos:

"21- $§ 2^{2}-$ A União pode instituir:
I - contribuições, nos termos do item I deste artigo, tendo em vista intervenção no domínio econômico e o interesse da previdência social ou de categorias profissionais."

4. - Algumas considerações podem ser tecidas sobre este texto. Em primeiro lugar. não se permitiu aos Estados e Municípios a instituição de contribuições, tolerando-se apenas as que decorressem do estabelecimento do regime previdenciário dos funcionários estaduais e municipais, como é o caso, por exemplo, da contribuição em favor do Instituto de Previdência do Estado do Rio Grande do Sul.

5. - Em segundo lugar, a doutrina tributária entendeu que, do dispositivo acima transcrito, poder-se-iam deduzir três espécies de contribuições especiais ou parafiscais, a saber, as decorrentes da intervenção da União no domínio econômico, tais como a em favor do I.A.A. e demais institutos federais congêneres, as no interesse da previdência social, como, por exemplo, a em favor do INSS, e as de interesse de categorias profissionais, como a contribuição sindical e a instituída pela $O A B$.

6. - Por 'outro lado, a inclusão dessas contribuições no capítulo relativo ao Sistema Tributário Nacional acentuou, confor me expressiva maioria dos autores e até mesmo de várias decisões de nossos tribunais, a sua natureza tributária. Além disso, com referência às contribuições, aplicava-se a faculdade prevista no item I do art. 21, relativa à importação de produtos estrangeiros, isto é, possibilitava-se ao Poder Executivo, nas condições e nos limites estabelecidos 